\title{
Detection of Genetically Modified Soybeans in Miso by Polymerase Chain Reaction and Nested Polymerase Chain Reaction
}

\author{
TZU-MING PAN* AND TSUNG-WEI SHIH \\ Department of Agriculture Chemistry, National Taiwan University, No. 1, Section 4, Roosevelt Road, Taipei 106, Taiwan, ROC
}

(Received: August 29, 2002; Accepted: October 18, 2002)

\begin{abstract}
In this study, we used polymerase chain reaction (PCR) to detect genetically modified Roundup Ready soybean (RRS) in miso. Several different DNA extraction methods had been tested. The CTAB method published by Lipp et al. and a commercial kit, Nucleospin Food, were used, because they had the most appropriate performance for miso sample. Four pairs of primers specific for the inserted genes and crop endogenous genes in RRS were applied in PCR. Using these primers, the method showed a false-negative result for the miso sample during a later period. When another more sensitive method, nested-PCR had been used, we obtained false-negative result for the sample in later fermentative stage. Since PCR and nested-PCR can not yield to positive results, using these two methods to detect transgenic components in miso is not efficient.
\end{abstract}

Key word: RRS, Miso, PCR, nested-PCR

\section{INTRODUCTION}

Since the mid 1990s, when the first genetically modified crop was on market, several identification methods were developed. These methods were classified into different groups which focusing DNA, proteins, or other specific analysis ${ }^{(1,2)}$. The official Sweden identification method, which was announced in 1998, focused on the detection of the genetically modified Roundup Ready soybean (RRS). A screening system, polymerase chain reaction (PCR), was applied to identify the $35 \mathrm{~S}$ promoter of the modified gene. A specific system was then applied to the identification of the specific gene, epsps, gene of 5enolpyruvyl-shikimate-3-phosphate synthase (EPSPS), for samples with 35S positive PCR results. For samples with 35S negative PCR results, a DNA check system was applied to identify the soybean's specific lectin gene. No soybean was identified in the samples if negative results were obtained. A specific system was then conducted for those samples with positive results. When the result was positive, RRS was identified; when negative, non-RRS soybean was identified $^{(3)}$. Since the PCR method bases on DNA, when DNA level is low, DNA integration is low. As the result, the present PCR inhibitors are hard to be separated and the accuracy and sensitivity of PCR methods will be dramatically interfered. This concern happens quite often in many processed foods, e.g. salad oil, fine soybean lethicin, starch extractants, et al. ${ }^{(4,5)}$.

Miso, a well-known traditional food that contains proteins and other nutrients, was made by fermenting soybean, rice, or wheat. During the manufacturing process,

\footnotetext{
* Author for correspondence. Tel:886-2-23630231 ext 3813 Fax:886-2-23627044; E-mail:tmpan@ntu.edu.tw
}

the contents of raw materials will change because of changes in temperature and $\mathrm{pH}$ value. Longer manufacturing process, 6-month fermentation period, is needed to make the miso than to make soybean milk and bean curd, etc. The DNA degradation and the existence of other inhibitors during miso fermentation processes will interfere the accuracy of PCR detection methods.

\section{MATERIALS AND METHODS}

\section{Chemical Reagents}

Chloroform and isopropanol were purchased from Merck Inc. (Darmstadt, Germany), and hexadecyltrimethyl ammonium bromide (CTAB) was bought from Sigma Inc (St Louis, Missouri, USA). DNA purification kit, Plant Genomic DNA Extraction Miniprep System, was obtained from Viogene Co. (Taipei, Taiwan) and Nucleospin Food was from Machery-Nagele, Germany (Distributed by Poster Co., Taipei, Taiwan). PrepMan ${ }^{\mathrm{TM}}$ Ultra Sampling Preparation Reagent was purchased from ABI Inc (Applied Biosystem, USA).

\section{Genetically Modified Soybeans, Reference Samples, and} Miso Samples

The reference standard of genetically modified soybeans was purchased from Sigma Co. (St. Louis, Missouri, USA). Traditional soybeans (MT21) and genetically modified soybeans (Roundup Ready ${ }^{\mathrm{TM}}$ soybean) were kindly provided by US Society of Soybean. Miso samples were manufactured in our lab ${ }^{(6)}$, samples were taken for analysis at specific time points during the 6-month fermen- 
tation period.

\section{DNA Purification}

The CTAB method, developed by Lipp et al., in $1999^{(7)}$, was followed for the extraction and purification of DNA. Similar CTAB methods developed by Dellaporta et $a l$,, in 1983 and Stewart et al., in 1993(8,9) were also evaluated.

In addition, several commercial DNA purification kits, including Plant Genomic DNA Extraction Miniprep System, Nucleospin Food and PrepMan ${ }^{\mathrm{TM}}$ Ultra Sampling Preparation Reagent, were also compared.

\section{Polymerase Chain Reaction and Nested Polymerase Chain Reaction}

Before performing PCR and Nested-PCR, the concentration of DNA sample solutions were analyzed at $\mathrm{OD}_{260}$ and $\mathrm{OD}_{280}$ by spectrophotometry ${ }^{(10)}$. After sample concentration is determined, it can be adjusted to the required level. The concentration of DNA sample solution was generally set at $1 \mathrm{ng} / \mu \mathrm{L}$.

The primers used in PCR are listed in Table 1. The reagents used were $1 \mathrm{X}$ reaction buffer (Pro Taq plus DNA polymerase), $200 \mu \mathrm{M}$ dNTP, $0.5 \mu \mathrm{M}$ primer (each), 1 unit polymerase (Pro Taq plus DNA polymerase) and $5 \mu \mathrm{L}$ DNA template. The final volume was adjusted to $25 \mu \mathrm{L}$. The PCR reaction condition was initial denaturation at $94^{\circ} \mathrm{C}$ for $3 \mathrm{~min}$, denaturation at $94^{\circ} \mathrm{C}$ for $30 \mathrm{sec}$, annealing at $55^{\circ} \mathrm{C}$ for $30 \mathrm{sec}$, and extension at $72^{\circ} \mathrm{C}$ for $30 \mathrm{sec}$ for 40 cycles. The finial extension was at $72^{\circ} \mathrm{C}$ for $1 \mathrm{~min}$.

As in nested-PCR, RR01/02 primer pair was used for the first PCR with 20 cycles. The other conditions were the same as the above PCR method. A 10X dilution of the DNA product derived from the first PCR was used as the DNA template in the second PCR, with RR04/05 as the primer pair. The remaining conditions were the same as the first PCR.

Five microliter of DNA product from PCR or nested-
PCR was used in electrophoresis, in which $2 \%$ or $3 \%$ agarose gel was applied.

\section{Restriction Enzyme Mapping Analysis}

The restriction enzyme mapping analysis developed by Lipp et al., 1999(7) was used in this study.

\section{RESULTS AND DISCUSSIONS}

\section{DNA Preparation and Purification}

Approximately $500 \mathrm{ng} \sim 1 \mu \mathrm{g}$ DNA fracture, 3,000 bp, was extracted from $100 \mathrm{mg}$ soybean sample when the CTAB method of Lipp et al. was used. The same DNA extraction procedure was also applied to miso samples. When compared with the other two CTAB methods, no significant difference of DNA yield and quality was observed. Since the CTAB method of Lipp et al. has been validated by many GMOs laboratories ${ }^{(7,13)}$ and it was comparatively easier to conduct, the method was chosen in this study.

Two different DNA-binding silica resins are evaluated in this study, Plant Genomic DNA Extraction Miniprep System and Nucleospin Food. The former one is not applicable in miso samples, because miso is starch-rich and heating would dramatically increase its viscosity. When extracting insoluble impurity in the shearing tube, the residue solution cannot be collected by the collection tube during centrifugation.

The same issue did not cause much concern when Nucleospin Food Kits were applied. The interference of starch pasting of sample can be improved by modifying study procedures, such as increasing $\mathrm{CF}$ buffer reagent volume and reaction time, increasing centrifugation force and time, etc. However, increasing CF buffer volume could also cause the supernatant volume to exceed $300 \mu \mathrm{L}$ after centrifugation. Therefore, most DNA in the sample solution cannot be used for further purification and the DNA yield decrease. Another factor which interferes the DNA yield of miso sample is the content of soybean. From

Table 1. Sequence of the primers used in PCR and nested-PCR

\begin{tabular}{|c|c|c|c|c|}
\hline Gene & Primer & Sequence 5'-3' & Amplicon (bp) & Reference* \\
\hline \multirow[t]{2}{*}{$35 \mathrm{~S}$ promoter } & $35 \mathrm{~S}-1$ & GCTCCTACA AATGCCATCA & 195 & 7 \\
\hline & $35 \mathrm{~S}-2$ & GATAGTGGGATTGTGCGTCA & & \\
\hline \multirow[t]{2}{*}{ CP4 EPSPS } & EPSPS B1 & TGATGTGATATCTCCACTGACG & 172 & 11 \\
\hline & EPSPS B2 & TGTATCCCTTGAGCCATGTTGT & & \\
\hline \multirow[t]{2}{*}{ NOS terminator } & NOS-1 & GAATCCTGTTGCCGGTCTTG & 180 & 7 \\
\hline & NOS-3 & TTATCCTAGTTTGCGCGCTA & & \\
\hline \multirow[t]{2}{*}{ Lectin } & LE103 & GCССТCТАСТССАСССССАТСC & 118 & 11 \\
\hline & LE104 & GCCCATCTGCAAGCCTTTTTGTG & & \\
\hline \multirow[t]{2}{*}{ E35S-CP4EPSPS } & RR02 & CCT TCG CAA GAC CCT TCC TCT ATA & 509 & 12 \\
\hline & RR01 & TGG CGC CCA TGG CCT GCA TG & & \\
\hline \multirow[t]{2}{*}{ CTP-CP4 EPSPS } & RR04 & CCC CAA GTT CCT AAA TCT TCA AGT & 180 & 12 \\
\hline & RR05 & TGC GGG CCG GCT GCT TGC A & & \\
\hline
\end{tabular}

* 7: Lipp et al., 1999

11: Collection of official methods under article 35 of the German Federal Foodstuffs Act. 1998.

12: Köppel et al., 1997 
the production procedure of miso, we know the soybean content is only $50 \%$. The soybean DNA extracted from miso is less than that from other sample. This should be taken into consideration when conducting studies afterwards.

The third reaction kit, PrepMan ${ }^{\mathrm{TM}}$ Ultra Sampling Preparation Reagent is different from the other two kits. Instead of utilizing DNA-binding silica resin, the mechanism of DNA purification is kept confidential as a business secret. As described in the operation procedure of the reaction kit, the purified DNA solution can be applied directly in PCR. Easy and fast operation are the biggest advantages of conducting large quantity of samples. However, we have found that the purified DNA solution is not clear in the test results of some food samples, indicating the existence of impurity in the DNA solution. The absorption of spectrophotometry at $\mathrm{OD}_{260 / 280}$ is far away from 1.8 2.0 as the general specification of highly purified DNA sample. The DNA solution cannot be quantified by spectrophotometry.

The comparison of DNA purification methods is listed in Table 2. CTAB method has low cost and high feasibility, but is not suitable for large quantity of samples as it's time consuming. Although commercial reaction kits have higher cost and are applicable to limited kind of samples, the operation of commercial kits is easy and fast. Based on the $\mathrm{OD}_{260 / 280}$ test results, no significant difference is observed in the purity of DNA solution obtained from CTAB method and Nucleospin Food DNA. Both methods are easily quantifiable by spectrophotometry. This is critical for the identification of positive or negative of PCR results. As for PrepMan ${ }^{\mathrm{TM}}$ Ultra Sampling Preparation Reagent, though it is fast, the product solution cannot be quantified. Therefore, in this study, we choose CTAB and Nucleospin Food to perform DNA purification. But, if not specified, CTAB method is used.

\section{Polymerase Chain Reaction}

The promoter $(35 \mathrm{~S})$, structure gene: epsps, gene of EPSPS (5-enolpyruvylshikimate-3-phosphate synthase), NOS terminator (nopaline synthase terminator) of transgenic RRS and soybean lectin gene sequences were amplified by PCR. The PCR products, using 35S1/2 and NOS $1 / 3$ as primer pairs, were analyzed with restriction enzyme mapping. The detection limit of RRS DNA is $0.1 \sim 1 \mathrm{ng}$, and 1 10 ng when $35 \mathrm{~S} 1 / 2$, and NOS1/3 was used as primer pairs, respectively. The detection limits are similar as those described in the previous studies ${ }^{(14)}$. The detection limit of soybean DNA is $1 \mathrm{ng} 10 \mathrm{ng}$ and $0.1 \mathrm{ng}$, when using EPSPS B1/B2 and LE103/104 as primer pairs, respectively.

Miso samples were obtained at different time points during the production process. After purification, DNA samples at different fermentation time points were analyzed with electrophoresis, and the PCR analysis was also performed. The changes of miso DNA samples at different time points are shown in Figure 1. The high molecular weight chromosomal DNA (lane 1 and lane 10) was destroyed during the manufacturing process of miso (lane 2 9 and 11 15), with the size of DNA fragments quickly decreased to $1,000 \mathrm{bp}$ or below. The longer the fermentation time, the more the DNA degrades. When the fermentation is nearly completed, most of the DNA fragments were degraded to $200 \mathrm{bp}$ or below.

In Figure 2, pattern a, b, c and d indicates the PCR results of RRS cloned gene in miso sample, using 35S1/2, EPSPS B1/B2, NOS1/3 and LE103/104 as primer pairs,

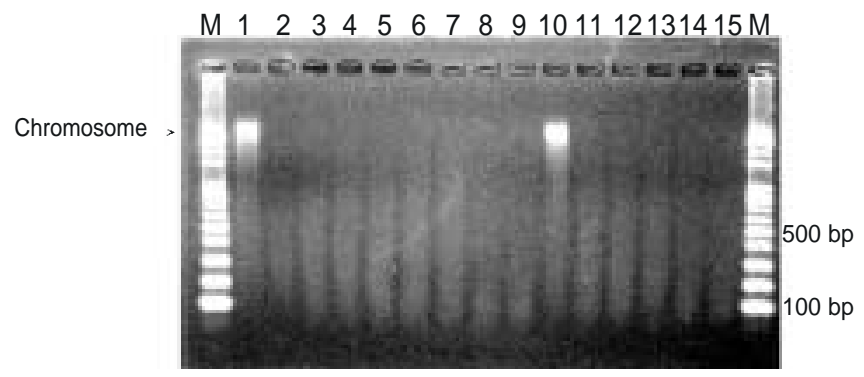

Figure 1. DNA extraction from miso samples

Lane M: Bio- $100^{\mathrm{TM}}$ DNA ladder; Lane 1, 10: steamed GM soybean and non-GM soybean; Lane 2, 11: intermediate products of miso made from GM soybean and non-GM soybean; Lane 3-9: miso samples made from GM soybean and sampled at the 10th, 30th, 70th, 100th, 120th, 150th, and 180th day; Lane 12-15: miso samples made from non-GM soybean and sampled at the 100th, 120th, 150th and 180th day

Table 2. Comparison of different DNA extraction methods' features

\begin{tabular}{|c|c|c|c|c|}
\hline \multirow[t]{3}{*}{ Extraction method } & \multirow[t]{3}{*}{ CTAB method } & \multicolumn{3}{|c|}{ Commercial kits } \\
\hline & & \multicolumn{2}{|c|}{ DNA-binding silica resin } & PrepMan $^{\mathrm{TM}}$ \\
\hline & & $\begin{array}{c}\text { Plant Genomic DNA } \\
\text { Extraction Miniprep System }\end{array}$ & Nucleospin Food & $\begin{array}{c}\text { Ultra Sampling } \\
\text { Preparation Reagent }\end{array}$ \\
\hline Expenses (NT/test) $^{1}$ & 4 & 72 & 120 & 49 \\
\hline Extraction time $(\min )^{2}$ & 240 & 60 & 60 & 15 \\
\hline $\begin{array}{l}\text { DNA recovery rate } \\
(\mu \mathrm{g} \text { DNA/mg sample) }\end{array}$ & 2.5 & Can't be detected & 0.5 & Can't be detected \\
\hline DNA purity $\left(\mathrm{OD}_{260 / 280}\right)$ & $\begin{array}{l}1.7 \sim 2.1 \\
\text { (n) }\end{array}$ & Can't be detected & $\begin{array}{c}1.8 \sim 2.0 \\
\text { Simple }\end{array}$ & Can't be detected \\
\hline
\end{tabular}

1: Cost of chemicals and materials

2: Rounded-off values 
(a)

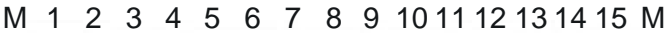
$195 \mathrm{bp}$

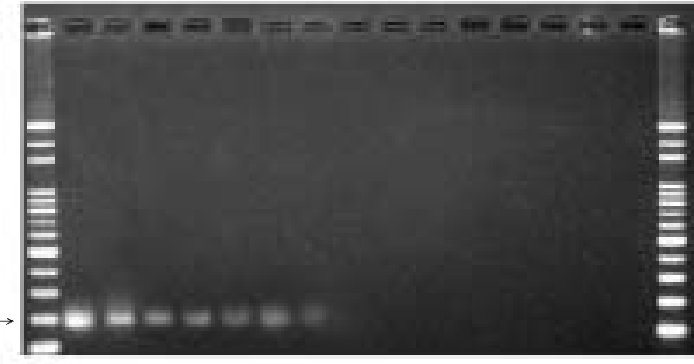

(c)
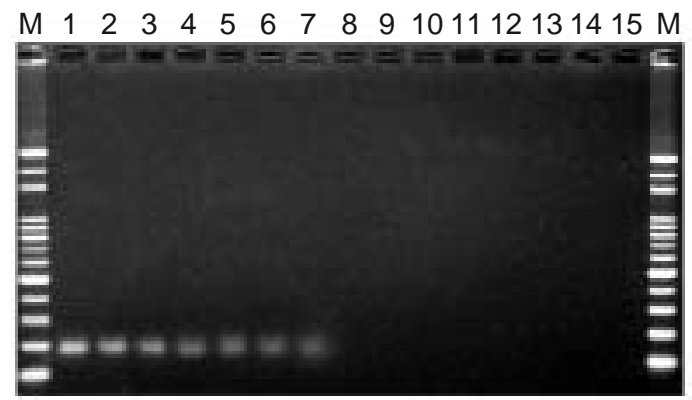

(b)

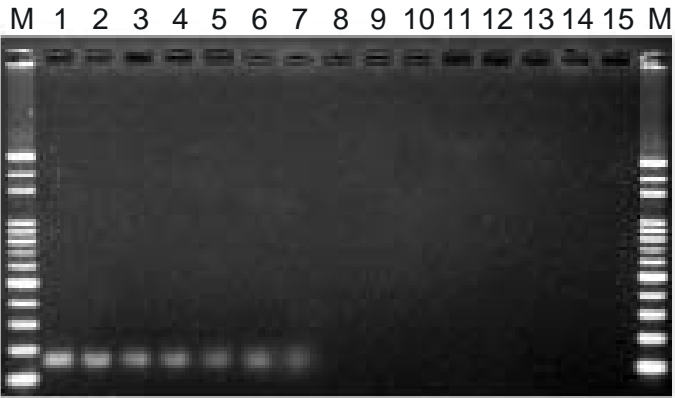

(d)
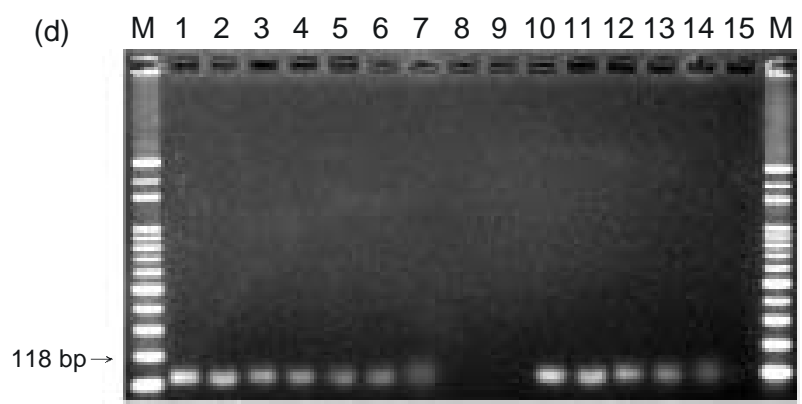

Figure 2. PCR products amplified from different gene region of miso samples with different primers Primer pairs: (a) 35S1/2, (b) EPSPS B1/B2, (c) NOS1/3, (d) LE103/104 Lanes: as described in Figure 1

$\begin{array}{llllllllllllllll}M & 1 & 2 & 3 & 4 & 5 & 6 & 7 & 8 & 9 & 10 & 11 & 12 & 13 & 14 & 15 M\end{array}$

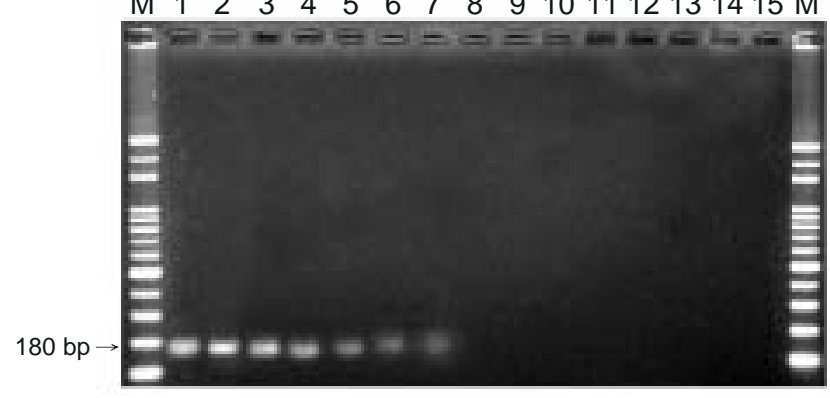

Figure 3. Nested-PCR products amplified from the region between 35S and EPSPS-gene of miso samples with primers RR04/05

Lane M: Bio- $100^{\mathrm{TM}}$ DNA ladder; Lane 1, 10: steamed GM soybean and non-GM soybean; Lane 2, 11: intermediate products of miso made from GM soybean and non-GM soybean; Lane 3-9: miso samples made from GM soybean and sampled at the 30th, 70th, 100th, 120th, 150th, 180th, and 210th day; Lane 12-15: miso samples made from non-GM soybean and sampled at the 120th, 150th , 180th and 210th day.

respectively. As the PCR patterns of a, b and $\mathrm{c}$ in Figure 2, RRS containing sample is positive until Day 100 of fermentation (lane 6). On Day 120 (lane 7), the analysis results are unstable and are not able to identify transgenic genes. On Day 150, all the results are false negative. Similar results were observed in soybean samples, as shown in pattern d in Figure 2. After Day 120 of fermentation, the analysis results are unreliable. From DNA degradation in Figure 1 and the 4 groups PCR analysis in Figure 2, failure to detect miso DNA is not due to the inefficiency of GMO primer pairs used, but the serious degradation of DNAs.

\section{Nested Polymerase Chain Reaction}

Nested-PCR was also tested because of its lower detection limit and higher specificity $(12,15)$. When nestedPCR was applied in miso sample, the results were indeed better than that of the traditional PCR. As shown in Figure 3, DNA samples are detectable through day 120 to day 150 . On day 150 (lane 7), the test result becomes unstable; and on day 180 (lane 8), DNA is completely undetectable and false-negative result is observed.

Although high specificity of nested-PCR prolongs the sample detection time during miso production process, false-negative result on day 180 is still observed. NestedPCR is ineffective to detect the transgenic genes in miso.

Although the CTAB method of Lipp et al. and the Nucleospin Food kit can be utilized in DNA purification of miso sample, serious degradation of DNA product is observed in this study. When the DNAs are analyzed by PCR and nested-PCR, results are unstable or false negative. In conclusion, PCR or nested-PCR is not effective in analyzing transgenic product of miso sample after 180 days of fermentation.

\section{ACKNOWLEDGEMENT}

This study is sponsored by the Department of Health, Administrative Yuan, ROC (project no. DOH90-TD-1096). The authors would like to thank Dr. Hui-Cheng Chen for his translation work. 


\section{REFERENCES}

1. Ahmed, F. E. 2002. Detection of genetically modified organisms in food. Trends in Biotech. 20: 215-223.

2. Gachet, E., Martin, G. G., Vigneau, F., and Mayer, G. 1999. Detection of genetically modified organisms (GMOs) by PCR: a brief review of methodologies available. Trends in Food Science \& Technology. 9: 380-388.

3. Anonymous. 1998. Schweizerisches Lebensmittelbuch (Swiss Food Manual). In: Bundesamt für Gesundheit (ed) Chap 52B: Molekularbiologische Methoden. Eidgenössische Drucksachen-und Materialzentrale, Bern, Switzerland.

4. Elke, A., Ferruccio, G., Petra, H., Hans, P., and Guy, V. D. E. 2002. Analytical methods for detection and determination of genetically modified organisms in agricultural crops and plant-derived food product. Eur. Food Res. Technol. 214: 3-26.

5. Ebbehøj, K. F., and Thomsen, P. D. 1991. Species differentiation of heated meat products by DNA hybridization. Meat Sci. 30: 221-234.

6. Shieh, Y. S. C. and Beuchat, L. R. 1982. Microbial changes in fermented peanut and soybean pastes containing kojis prepared using Aspergillus oryzae and Rhizopus oligosporus. J. Food Sci. 47: 518-522.

7. Lipp, M., Brodmann, P., Pietsch, K., Pauwels, J. and Anklam, E. 1999. IUPAC collaborative trial study of a method to detect genetically modified soybeans and maize in dried powder. J. AOAC Int. 82:923-928.

8. Dellaporta, S. L., Wood, J., and Hicks, J. B. 1983. A plant DNA minipreparation: Version II. Plant Mol. Biol. Rep. 1: 19-21.

9. Stewart, C. N. Jr. and Laura E. Via. 1993. A rapid CTAB DNA isolation technique useful for RAPD fingerprinting and other PCR applications. Biotechniques. 14: 748-749.
10. Sambrook, J., and Russell, D. W. 2001. Molecular cloning: A laboratory manual. Cold Spring Harbor Laboratory Press. Cold Spring Harbor. New York.

11. Collection of official methods under article 35 of the German Federal Foodstuffs Act. L23.01.22-1. 1998. Detection of a genetic modification of soybeans by amplification of the modified DNA sequence by means of the polymerase chain reaction (PCR) and hybridization of the PCR product with a DNA probe. BgVV. Berlin. Germany.

12. Köppel, E., Stadler, M., Lüthy, J. and Hübner, P. 1997. Sensitive method for the detection of the genetically engineered soybean Roundup Ready ${ }^{\mathrm{TM}}$. Mitt Gebiete Lebensm Hyg. 88: 164-175.

13. Lin, H. Y., Chiueh, L. C. and Shih, D. Y. C. 2000. Detection of genetically modified soybeans and maize by the polymerase chain reaction method. J. Food Drug Anal. 8: 200-207.

14. Hübner, P., Studer, E., Häfliger, D., Wolf, C., and Looser M. 1999. Detection of genetically modified organisms in food: critical points for quality assurance. Accred Qual. Assur. 4: 292-298.

15. Meyer, R., and Jaccaud, E. 1997. Detection of genetically modified soya in processed food products: development and validation of PCR assay for the specific detection of glyphosate-tolerant soybeans. In: Amado R, Battaglia R (eds) Proceedings 9th European Conference on Food Chemistry. Authenticity and adulteration of food - The analytical approach vol 1 . Interlaken, Switzerland 24-26 September 1997. Nestle', Lausanne, Switzerland, pp 23-28. 